\title{
OVERDISTENTION OF THE URINARY BLADDER DURING AND AFTER ANAESTHESIA
}

\author{
Gertie F. MaRX, M.D., and Lous R. ORKin, M.D."
}

GeNERAL ANAESTHESIA is commonly associated with decreases in renal blood flow, filtration rate, and excretion of water and electrolytes. ${ }^{1}$ The magnitude of these changes depends on two factors: the depth of anaesthesia and the state of the patient's hydration. The lighter the plane of anaesthesia, the less pronounced are the depressions in renal functions. The more normal the patient's fluid balance, the less likely is anaesthesia to disturb renal activity. Patients anaesthetized with halothane developed renal effects at all anaesthetic levels when their fluid balances were negative, but only at high anaesthetic concentrations when they were well hydrated. ${ }^{2}$

Marked shifts in body fluids have been demonstrated during major surgical procedures associated with traumatic insults or shock. ${ }^{3}$ Considerable amounts of fluid are sequestered within the body and are not available to meet metabolic needs for three to five days postoperatively. However, if balanced salt solutions are administered during the course of such surgery at the rate of 7 to $10 \mathrm{ml} / \mathrm{kg}$. body weight per hour, plasma sodium concentration and active fluid balances are maintained in these patients, and urinary output remains good in the postoperative period. 4 In operative procedures of equal duration, but less traumatic in nature, little or no internal redistribution of fluid takes place. If intravenous infusions are administered in large amounts, the kidney rids the body of the excess fluid load. With the present technique of employing light planes of general anaesthesia, "antidiuresis" does not readily develop. Under these circumstances, the volume of urine is a function of the load, and considerable quantities of urine accumulate in the bladder.

Overdistention of the urinary bladder may cause respiratory and/or circulatory changes in the patient during the course of anaesthesia, and excitement or restlessness during the recovery period. Overdistention of the urinary bladder, secondary to excessive intravenous fluid therapy, was associated with increased resistance to ventilation, a rise in blood pressure, or postoperative excitement in four patients at the Bronx Municipal Hospital Center in 1965. These signs and symptoms were relieved immediately following catheterization and decompression of the bladder.

\section{Case I}

\section{Case Reports}

A 46-year-old woman in good general health underwent a right radical mastectomy under semi-closed nitrous-oxide-oxygen-halothane anaesthesia via a cuffed

"Department of Anesthesiology of the Bronx Municipal Hospital Center, Albert Einstein College of Medicine, New York, New York.

Can. Anaes. Soc. J., vol. 13, no. 5, Sept. 1966 
orotracheal catheter. Her blood pressure, normally about $140 / 80$, was reduced to $80 / 50$ with an infusion of trimethaphan (Arfonad) and maintained at this level for a period of two hours. E.C.G. monitoring confirmed a regular sinus rhythm at 72 to 88 beats per minute throughout. E.E.G. monitoring indicated a pattern commensurate with light anaesthesia. During the four hours of anaesthesia and three and one half hours of surgery, the patient received $1700 \mathrm{ml}$. of lactated Ringer's solution with 5 per cent dextrose intravenously. The estimated blood loss was less than $300 \mathrm{ml}$.

Ventilation was assisted at the rate of 16 per minute during the first two hours. Increased resistance to inflation of the lungs developed gradually. Succinylcholine 0.1 per cent was infused for the next 30 minutes, and ventilation was controlled for the remainder of surgery, but the resistance to inflation continued to increase. Breath sounds were normal bilaterally. Suctioning of the endotracheal catheter, deflation and re-inflation of the cuff did not effect any change. The patient's blood seemed to be well oxygenated. Attempts at arterial puncture were technically unsuccessful. The cause of the increased resistance remained obscure.

When the drapes were removed at the end of surgery, the abdomen was protruding markedly. Examination disclosed a greatly distended bladder; catheterization yielded $1200 \mathrm{ml}$. of urine. Immediately thereafter, inflation of the lungs was easy, and the sense of resistance had completely disappeared. Spontaneous ventilation returned, was measured as adequate, and the endotracheal catheter was removed. The patient left the operating room awake, with a blood pressure of $150 / 84$, a pulse rate of 88 , respiratory rate of 22 . Recovery was uneventful.

\section{Case II}

A 67-year-old man had a craniotomy performed under light nitrous-oxideoxygen-halothane anaesthesia administered via cuffed orotracheal catheter with a semi-closed technique. Moderate hyperventilation was employed. A meningioma was found and surgically removed. After the first four hours of surgery, the blood pressure which had stabilized around 110/80 slowly rose to 140/90; pulse rate remained unchanged at 72 beats per minute. Concurrently, resistance to inflation of the lungs developed.

Inspection revealed the patient to be straining as though attempting to urinate, and there was a mass in his lower abdomen. Catheterization produced $650 \mathrm{ml}$. of urine and was followed by immediate return of the blood pressure to its previous level and by cessation of straining. A review of the fluid administration showed that $1300 \mathrm{ml}$. of lactated Ringer's solution had been administered; estimated blood loss was less than $500 \mathrm{ml}$.

\section{Case III}

A 54-year-old neurotic woman was operated on for extraction of cataract. Light surgical anaesthesia was maintained with a semi-closed nitrous-oxide-oxygenhalothane technique via a cuffed orotracheal catheter for two hours and twenty minutes. The patient was awake, quiet, and co-operative on arrival in the recovery room. She received phenergan $25 \mathrm{mg}$. intramuscularly as a prophylactic measure because of her neurosis. Approximately one hour later she became markedly excited and restless. 
The lower abdomen was noted to be enlarged. Eight hundred and fifty millilitres of urine were removed by catheterization, and the patient became calm again. She had been infused with $950 \mathrm{ml}$. of lactated Ringer's solution.

\section{Case IV}

A six-week-old infant, weighing $2.6 \mathrm{~kg}$, underwent repair of a congenital meningo-encephalocele. Nitrous-oxide-oxygen-halothane anaesthesia was administered via an orotracheal catheter with a modified Rees technique. ${ }^{5}$ Body temperature was slowly reduced to $34^{\circ}$ centigrade; respirations were controlled; heart rate was between 120 and 140 per minute. During four hours and twenty minutes of anaesthesia and three and one half hours of surgery, the infant received $200 \mathrm{ml}$. of $1 / 3$ normal saline solution intravenously. The measured blood loss ( $90 \mathrm{ml}$.) was replaced periodically by $5 \mathrm{ml}$. increments of whole blood.

At the end of the procedure, the infant was breathing spontaneously 36 times per minute, and the tidal volume measured $16 \mathrm{ml}$. She was placed in an isolette with high humidity, 40 per cent oxygen, and external heat. The 1/3 normal saline infusion was continued at the rate of $30 \mathrm{ml}$. per hour. During her first two hours in the recovery room, the infant's respiratory rate remained at 40 per minute and her heart rate at $\mathbf{1 4 0}$ per minute. Gradually, respirations became shallow and labored at the rate of 60 per minute, and the heart rate rose to 160 . Examination of the heart and lungs did not reveal any abnormality. However, the abdomen was distended, and the diaper was dry. It was apparent that the infant had not voided for several hours. Catheterization drained $60 \mathrm{ml}$. of urine. There was an immediate decrease in respiratory rate to 40 and in heart rate to 132 . Thereafter, the infant voided spontaneously, and heart and respiratory rates remained normal.

\section{Discussion}

The value of lactated Ringer's solution during major operations or resuscitation from shock has been demonstrated many times. ${ }^{4}$ However, if the surgical procedure is such that fluid shifts do not occur, and if the patient is lightly anaesthetized, one must expect to see the consequences of an overdistended bladder. These may be reflected in respiratory and/or circulatory changes, and in restlessness or excitement. Measures to treat such changes symptomatically should not be undertaken until this chain of events has been eliminated.

Cystometrograms of normal adults revealed that the first desire to void occurs when the bladder holds between 150 and $250 \mathrm{ml}$. of water. At a volume of 300 $\mathrm{ml}$., the person feels "that he would rather not take any more fluid into his bladder." infant weighing $21 / \mathrm{kg}$. may be expected to have a bladder capacity of less than $20 \mathrm{ml}$. Thus, at the time of catheterization, the four patients' bladders were overfilled to two to four times their normal volume.

As the bladder fills, the upper wall rises. ${ }^{\theta}$ An overdistended bladder may push the abdominal contents upwards against the diaphragm and lead to a diminution of the chest cage and a decrease in compliance. This is most likely when the stomach or the intestines are distended with gas or fluids. ${ }^{8}$ The overdistended urinary bladder has been compared to the pregnant uterus. ${ }^{2}$ However, uterine 
enlargement is gradual, and compensatory broadening of the chest cage develops during the course of gestation. In addition to the mechanical effects, the overdistended bladder may influence respiration by causing the patient to splint his abdominal musculature in his involuntary effort to micturate. A third mechanism is that of a reflex response. Cardiopulmonary function studies in 22 anaesthetized dogs before and during distention of the urinary bladder demonstrated in fifteen of them a reduction in total thoracic compliance during distention. The group of dogs with decreased compliance also had increased aortic and pulmonary arterial pressures, increased cardiac output, inconsistently increased central blood volume, and increased heart rate. It was concluded that these results establish an effect of distention of the bladder on cardiopulmonary function, and it was suggested that a neural or humoral reflex mechanism is in operation. ${ }^{10}$ The presence of a urinary vesico-vascular reflex has also been confirmed in normal man. The mechanical stimulus of overdistention of the bladder as well as thermal or chemical stimulation of pain receptors in the bladder wall were shown to cause a rise in systolic and diastolic pressures. ${ }^{11}$ It has also been recognized that during narcosis with intravenous barbiturates responses to minor stimuli are exaggerated if the patient has a full bladder. ${ }^{12}$

Spontaneous rupture of a normal bladder is very rare. However, "it does not take much of a blow to rupture an overdistended bladder. ${ }^{13}$ An injury of this type may occur during transfer of an anaesthetized patient from operating table to recovery bed or be inflicted by the patient during an emergence excitement stage.

\section{Summary AND Conclusions}

Four cases are reported of patients who developed respiratory difficulty, a rise in blood pressure, or excitement during or after "non-traumatic" surgery under light nitrous-oxide-oxygen-halothane anaesthesia while receiving balanced salt solutions, intravenously, in excess of the estimated or measured blood loss. The complications were attributable to overdistention of the urinary bladder and were instantaneously relieved following removal of the urine by catheterization.

In view of the trend to maintain light planes of general anaesthesia and to use balanced salt solutions for intravenous therapy, it is recommended to encourage emptying of the bladder prior to the onset of anaesthesia, and to gauge fluid replacement according to the expected extent of sequestration and blood loss. The use of an open indwelling urinary catheter may be desirable during prolonged surgery.

Failure to recognize overdistention of the urinary bladder may lead to erroneous therapy of the ensuing signs and symptoms.

\section{RÉSUMÉ}

Nous racontons l'histoire de quatre malades qui ont présenté des troubles respiratoires, une élévation de la tension artérielle, de l'excitation durant ou après de la chirurgie "non traumatique" sous anesthésie légère au protoxyde d'azote, oxygène et halothane en même temps qu'ils recevaient une solution salée 
isotonique, par voie endoveineuse, en excès des pertes sanguines estimées ou mesurées. Ces complications ont été attribuées à la surdistension vésicale et ont cédé instantanément à la suite d'une catéthérisme vésical.

Etant donné la tendance à maintenir des plans superficiels d'anesthésie générale et à administrer des solutions salées isotoniques en thérapie endoveineuse, il est à conseiller de vider la vessie avant l'induction de toute anesthésie et de calculer le remplacement des liquides d'après la perte de sang prévue. Au cours de la chirurgie de longue durée, il serait même désirable d'installer. une sonde à demeure et de la laisser ouverte.

Ne pas diagnostiquer une surdistension vésicale peut faire instituer une fausse thérapie pour corriger les symptômes mentionnés ci-haut.

\section{REFERENCES}

1. Papper, S. \& Pappen, E. M. The Effects of Preanesthetic, Anesthetic, and Postoperative Drugs on Renal Function. Clin. Pharmac. \& Therap. 5: 205 (1964).

2. BarRY, K. G.; Mazze, R. I.; \& Schwartz, F. D. Hydration during and after Surgery. New England J. Med. 270: 1371 (1964).

3. Shmies, T.; Wrillams, J.; \& Brown, F. Acute Changes in Extracellular Fluids Associated with Major Surgical Procedures, Ann. Surg. 154: 803 (1961).

4. Jenknns, M. T.; Grosecke, A. H.; \& Shrmes, G. T. Electrolyte Therapy in Shock: Management during Anesthesia, Chap. 3 in Orkin, L. R. Clinical Management of the Patient in Shock, Clinical Anesthesia, Vol. 2. Philadelphia: F. A. Davis Company (1965).

5. ReEs, G. J. Aspects of Anaesthesia in Infants and Neonates, Chap. 23 in Evans, F. T. and Gray, T. C. General Anaesthesia, 2nd ed. Washington: Butterworth Inc. (1965).

6. Greene, L. F. \& EMMert, J. L. Neurophysiology of Micturition, Chap. 4 in Campbell, M. G. Urology, Vol. 1, 2nd ed. Philadelphia: W. B. Saunders Company (1963).

7. Campreil, M. F. Pediatric Urology, Vol. 1. New York: Macmillan Company (1937).

8. Newhan, H. Personal communication.

9. Stoutz, H. L. Massive Edema of the Lower Extremities Associated with Overdistention of the Bladder. J. Urol. $36: 563$ (1961).

10. Honwriz, L. D.; KMM, B. M.; \& GRAY, F. D. Cardiopulmonary Effects of Distention of the Urinary Bladder. Am. Heart J. 71: 346 (1966).

11. LAPIDES, J. \& Lovegrove, R. H. Urinary Vesicovascular Reflex. J. Urol. 44: 397 (1965).

12. Dundee, J. W. The Anesthetist and Analgesia, Chap. 3 in Eckenhoff, J. E. Science and Practice in Anesthesia. Philadelphia: J. B. Lippincott Company (1965).

13. Crossie, A. H. Rupture of the Urinary Bladder. J. Urol. 12: 431 (I924). 